\title{
Accounting for economies of scope in performance evaluations of university professors
}

\author{
Kristof De Witte \\ Nicky Rogge \\ Laurens Cherchye \\ Tom Van Puyenbroeck
}
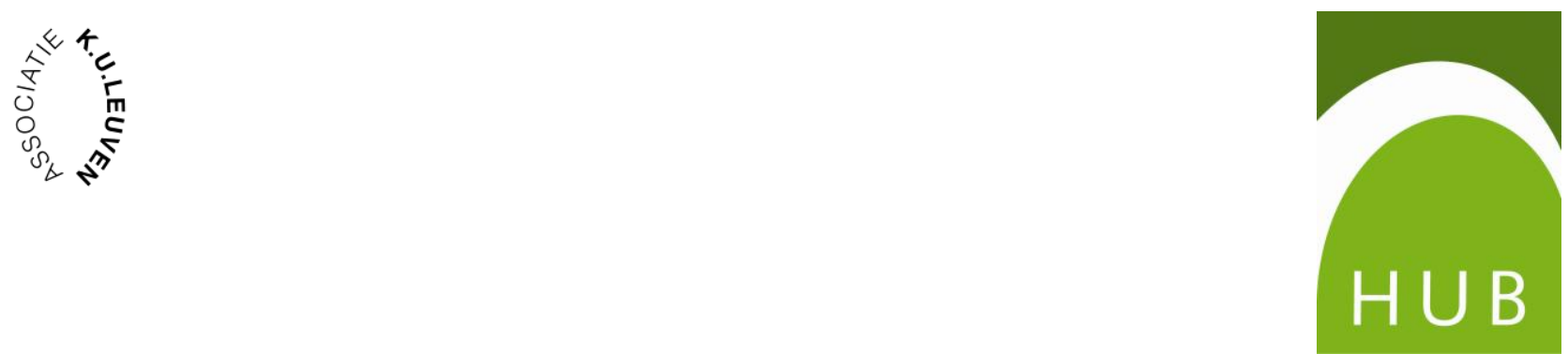


\title{
Accounting for economies of scope in performance evaluations of university professors
}

\author{
Kristof De Witte ${ }^{\ddagger \delta}$, Nicky Rogge ${ }^{\star * 1}$, Laurens Cherchye $e^{\ddagger \dagger}$ and Tom Van Puyenbroeck ${ }^{\ddagger *}$
}

\author{
(\$): Katholieke Universiteit Leuven (KULeuven) \\ Faculty of Business and Economics \\ Naamsestraat 69, 3000 Leuven (Belgium); \\ (ס): Maastricht University \\ Top Institute for Evidence Based Education Research \\ Kapoenstraat 2, MD 6200 Maastricht (the Netherlands) \\ Kristof.dewitte@econ.kuleuven.be \\ $(\dagger)$ : Tilburg University \\ Department of Econometrics and OR \\ P.O. Box 90153, 5000 LE Tilburg (The Netherlands); \\ (*): Hogeschool-Universiteit Brussel (HUBrussel) \\ Centrum voor Duurzaam Ondernemen (CEDON) \\ Center for Educational Research \& Development (ER\&D) \\ Warmoesberg 23, 1000 Brussels (Belgium)
}

\begin{abstract}
Teaching and research are widely regarded as the two key activities of academics. We propose a tailored version of the popular Data Envelopment Analysis methodology to evaluate the overall performance of university faculty. The methodology enables accounting for the potential presence of economies of scope between the teaching and research activities. It is illustrated with a dataset of professors working at a Business \& Administration department of a university college. The estimation results reveal that overall the performance scores of faculty decrease if we allow for spillovers from research to teaching and vice-versa.
\end{abstract}

Keywords: Teaching-research nexus, Data envelopment analysis, Conditional efficiency, Economies of scope, Higher education.

JEL-classification: C14, C25, I21

\footnotetext{
${ }^{1}$ Corresponding author. Tel.: 00326098834

E-mail address: Nicky.Rogge@hubrussel.be
} 


\section{Introduction}

With institutional budgets being tight and resources being scarce, the mainly 'laissez-faire' approach towards the higher education sector declined considerably in the last decades. Like in other public sectors, there has been an increasing movement towards accountability in higher education. As a result of this surge in demand for more quality in teaching and research, the majority of universities and colleges initiated several changes in the strategic management and the institutional policies. One example is the establishment of internal quality assurance systems to evaluate the faculty teaching and research performances. Under the motto "you cannot manage what you cannot measure", faculty evaluation committees and academic administrators more and more rely on the outcomes of teaching and/or research performance evaluations to judge on a faculty member's competence (as both activities are essential aspects of professorship).

Two important questions in the performance evaluations of university faculty are (1) whether professors who combine teaching and research activities do (not) have an advantage compared to their colleagues who are only asked to teach or do research and (2) if scope economies between teaching and research are observed, how should the overall performance of professors be assessed?

Regarding the first question, the debate on the precise relationship between teaching and research - in particular whether teaching tasks hinder good research or whether research benefits the quality of teaching - is a long-standing and highly controversial one. In the literature, there are two schools of thought, namely those who advocate the existence of a positive teaching-research nexus and the sceptics. The believers of a positive teaching-research relationship support the idea that research and teaching are mutually enforcing in the sense that teaching benefits research productivity and research benefits teaching effectiveness. As such, teaching and research go together in an essential and symbiotic way (Neumann, 1992; Kremer, 1990; and Westergard, 1991). The sceptics, on the other hand, highly doubt that teaching and research are positively intertwined (e.g., Hattie and Marsh, 1996; Feldman, 1987, Marsh and Hattie, 2002). According to their viewpoint, the widely held belief that teaching and research are inextricably entwined is an enduring myth. At best, research and teaching are very loosely coupled (Hattie \& Marsh,1996 p. 529). ${ }^{2}$

Both the believers and the non-believers refer to academic studies to buttress their viewpoint. Those who support the positive teaching-research relationship typically refer to the outcomes of qualitative studies which demonstrate that academics themselves (but also other university stakeholders such as students, university administrators, etc.) experience a positive relationship between teaching and research. An example of such a qualitative study is Becker and Kennedy (2005) that examined how several eminent economists believe teaching affects research and found that a large majority of the

\footnotetext{
${ }^{2}$ Some of the sceptics even go further claiming that teaching and research are not complementing but rather substituting activities, with the professor being forced to choose one activity over the other (e.g., Barnett, 1992; Massy and Zemsky, 1994; etc.).
} 
questioned economists (i.e., $85 \%$ of the respondents) believe that teaching enhanced their research. ${ }^{3}$ The non-believers frequently refer to the outcomes of the studies that employ quantitative approaches (such as correlation analyses) to study the teaching-research nexus. Hattie and Marsh are well-known examples of scholars who oppose to the notion that teaching and research are mutually enforcing activities. Their disbelief is based on the outcomes of several quantitative studies by their hand which consistently showed that there is no or only a low positive correlation between the professors' teaching effectiveness and research productivity. ${ }^{4}$ However, even Hattie and Marsh recognized that the presence of an overall zero or small positive correlation between teaching effectiveness and research productivity does not mean that for some professors, economies of scope do not exist between their teaching and research activities (Hattie and Marsh, 2004 p.1). In particular, individual faculty members may differ in their beliefs and conceptions on how to fill in and combine the teaching and research activities. As such, there can be considerable variance at the level of individual academics, with for some professors teaching and research being mutually enforcing (making them excellent teachers and productive researchers) and for other professors teaching hampering good research (the result being that they are possibly effective teachers, but not-so-excellent researchers) or research interest hampering effective teaching (so excellent researcher but not-so-effective teacher).

The question of whether there is comparative advantage for professors who do both teaching and research compared to their colleagues who only teach or do research, is thus difficult to answer straightforwardly. Whereas some studies seem to suggest that teaching and research are mutually enforcing in the sense that teaching benefits research productivity and research benefits teaching effectiveness, other studies point out that teaching and research are probably separate and distinct activities.

Given the ambiguity on the precise association between teaching and research, performance evaluation and reward systems for the professor should take into account that (at least for some professors) teaching and research activities may partially overlap (Centra, 1993 p. 2). Performance appraisal systems should recognize that economies of scope between teaching and research could be present and that this could affect both the quantity and the quality of the professor outputs in both activities. Performance evaluation systems should consider the entire scope of a professor's work: that is, evaluation systems should preferably account for both the teaching and research dimensions of the professor's work as well as the complex nature of the interrelation between both activities (Scott, 1998; Vidal \& Quitanilla, 2000). This paper presents a way to do so.

\footnotetext{
3 Other examples of qualitative studies that focused on the academics' beliefs and conceptions on the teachingresearch nexus include Smeby (1998), Noser et al. (1996), and Robertson and Bond (2001). Jenkins et al. (1998), Neumann $(1993,1996)$ and Lindsay et al. (2002) are examples of qualitative studies that examined the opinions of students on the teaching-research nexus.

4 In a meta-analysis, Hattie and Marsh (1996) reviewed and analyzed the quantitative studies that were performed up to the mid 90s (i.e., 58 studies), and found an overall correlation of +0.06 and a $95 \%$ confidence interval between +0.061 and +0.066 (after correcting for overemphasis on a few studies with a large number of computed correlations, the average correlation rose to around +0.11 ).
} 
Concerning the second question on how to account for the potential presence of economies of scope between teaching and research in the overall performance evaluations of university faculty, we advocate the non-parametric model by Cherchye et al. (2008). This model draws on Data Envelopment Analysis methodology (DEA) and is closely related to a DEA model that was originally proposed by Bogetoft (1996). DEA is an efficiency measurement technique originally developed by Farrell (1957) and put into practice by Charnes et al. (1978). The scope economies model of Cherchye et al. (2008) is appealing to measure the overall performances of university professors because of its non-parametric nature. In particular, the model allows studying the complex production processes of academics (i.e., the academic combining his role as teacher and researcher in his/her daily activities) without the need for precise a priori information or assumptions (such as linearity, etc.) on the functional relationship between teaching and research. The version of the model that is used in this paper is based on new insights of Cazals et al. (2002), Daraio and Simar (2005, 2007a, 2007b), and De Witte and Kortelainen (2009). Specifically, estimations of the performance scores of professors are not only accounting for the possible presence of scope economies but also are less sensitive to atypical observations and are corrected for the differences in background conditions (e.g., professor gender and age).

The practical usefulness of the model is illustrated on a sample of 155 academics working at a Business \& Administration faculty of a large university college in Brussels (Belgium). This university college can be compared to the 'new' polytechnic universities in the UK and the colleges in the US. In particular, it used to be an educational institution with exclusive focus on teaching, but recently, thanks to the Bologna reforms (and an academization process initiated by the European Union), it became increasingly research-oriented.

The remainder of this paper is laid out as follows. In the next section, we give a brief overview of the studies that have investigated the relationship between teaching and research. Following the literature, we distinguish between empirical and qualitative studies. Section 3 discusses the data for the professors working at the faculty of Business and Administration of the university college under study. The next section then introduces the model of Cherchye et al. (2008) that allows for estimating the overall performance of professors while accounting for possible economies of scope between teaching and research. We further adjust this model using insights of Cazals et al. (2002) and Daraio and Simar $(2005,2007 \mathrm{a}, 2007 \mathrm{~b})$ to make the outcomes of the performance evaluations (1) less sensitive to outliers or inaccuracies in the data and (2) corrected for the influence of background variables (i.e., the gender and the age of the professor). The fifth section presents the outcomes of the overall performance evaluations of the academics active at the faculty of Business \& Administration of the university college. In the final section, we offer some concluding remarks and some directions for further research. 


\section{Literature}

Many papers have been written to examine the relationship between teaching and research roles of university professors. Most of the research was done in the 1970s and the 1980s. However, recently, interest in the subject has been renewed, stimulated perhaps by the increased interest of both practitioners and policy makers. In this section, we present the most important findings of these studies. We distinguish between studies using quantitative methodologies and studies following qualitative approaches. As Figure 1 illustrates findings from previous quantitative and qualitative studies on the teaching-research nexus are mixed.

\section{$<$ Figure 1 about here >}

The quantitative studies typically compute the linear correlation coefficient between the outputs of the teaching and research activities, respectively research productivity and teaching effectiveness. The main findings of the studies using quantitative approaches are nicely reviewed and analyzed in some interesting literature reviews: Feldman (1987), Hattie and Marsh (1996), Allen (1996), and Braxton (1996). In general, studies found that teaching and research (i.e., the output of both activities) are at maximum marginally correlated. For instance, in a meta-analysis, Hattie and Marsh (1996) reviewed and analyzed 58 quantitative studies (with a total of estimated 498 correlations) that were performed up to the mid $90 \mathrm{~s}$. They found a majority of the studies reporting average correlations that are not significantly different from zero. A few other studies computed average correlations that are significantly positive (and only a very small minority reporting significantly negative average correlations). After aggregating the correlations of the studies, Hattie and Marsh (1996) found an overall correlation of +0.06 and a $95 \%$ confidence interval between +0.061 and +0.066 . After correcting for overemphasis on a few studies with a large number of computed correlations, average correlations rose to around +0.11 . Allen (1996) reported a similar result with an average correlation of +0.107 .

The qualitative studies frequently use semi-structured, in-depth interviews to collect information about the perceptions, attitudes, or opinions of the different university stakeholders on the teachingresearch nexus. Typical stakeholders of a university include academic administrators (Neumann, 1992, 1993; and Rowland, 1996), academics (Smeby, 1998; Noser et al., 1996; and Robertson \& Bond, 2001), and students (Jenkins et al., 1998; and Lindsay et al., 2002). Qualitative studies usually report a strong belief among university stakeholders that teaching and research are positively related. Specifically, most respondents indicate that this positive relationship predominantly works in one way, with the impact of research on teaching being far more important than the other way around.

Both the believers and the sceptics formulated several theories and arguments in support of their respective viewpoints. The conventional wisdom model and the " $G$ " model are examples of models in support of a positive relationship between teaching and research. The conventional wisdom model argues that the positive nexus is 'obvious' because the majority of the academics (i.e., the people who experience the impact of combining both activities in practice every day) are strongly convinced that both activities are mutually enforcing. Examples of studies supporting this model are Neumann 
(1992), Kremer (1990) and Halsey (1992). For instance, Neumann (1992) reported that the majority of the academics in his sample having no doubts about the positive link between teaching and research. Halsey (1992) found similar results with approximately $90 \%$ of the academics questioned in his study, claiming that it is impossible for academics to be good teachers without being active in research. The "G" model formulates another argument as to why the teaching-research nexus should be positive. According to this model, there is a strong overlap between the abilities to be a good teacher and the abilities to be a productive researcher. Among others, Westergard (1991) listed examples of attitudes, values, and competencies which are underlying both good teaching and good research (e.g., the spirit of active enquiry).

An example of an argument as to why the teaching-research nexus should be negative are developed by, among others, Fox (1992) and Trice (1992) who argue that, given the scarcity of time, effort, and energy and the high labor intensity of both teaching and research, it is nearly impossible for an academic to excel in both activities. Instead, academics have to trade-off between investing scarce resources in teaching or in research. In the literature, the model has been alternatively labelled 'the scarcity model'. Another theoretical model in support of an inverse teaching-research association is 'the different personality model' which claims that teaching and research require different personality traits and orientations that are unlikely to be found in the same person. Rushton et al. (1983) examined two samples of university professors and found the recurrent finding that creative researchers are, in general, ambitious, enduring, seeking definiteness, dominant, showing leadership, aggressive, independent, non-meek, and non-supportive whereas effective teachers are typically liberal, sociable, showing leadership, extraverted, non-anxious, objective, supporting, non-authoritarian, non-defensive, intelligent, and aesthetically sensitive. A brief comparison of these typical profiles already reveals that some key characteristics of highly productive researchers and effective teachers cannot simultaneously be present in one person. Another argument in support of a negative correlation between teaching and research is that the latter can breed a kind of narrowness in which the academic has a good knowledge in a specific area at the cost of more general knowledge.

The literature also provides some arguments supporting a zero relationship between teaching and research. One such a view is provided by among others Barnett (1992) and Rugarcia (1991) who argue that teaching and research are completely different enterprises and, therefore, it should not be expected that the performances of academics in both activities to correlate positively or negatively. Another theoretical reasoning is that researchers and teachers have entirely different personality profile. According to this model, teachers and researcher are completely different types of people. By consequence, they have only a few personality-attributes in common (note that this argument overlaps with the one of the 'difference personality model'). For a more elaborated discussion of the reasoned arguments for the several positions on the teaching-research nexus, we refer to among others, Hattie and Marsh (1996) and Zaman (2004). 


\section{Data}

The analysis is applied at a large university college in Brussels. This university college resembles in many ways to the 'new' (polytechnic) universities in the UK and the colleges in the US. ${ }^{5}$ In particular, it used to be an educational institution with a predominant focus on teaching, whereas recently, following the Bologna reforms, the university is increasingly research oriented. As a result of these recent changes, the university college under study has developed a large interest in evaluating the performances of its faculty staff, both in terms of teaching performance and of research performance.

The sample of observations consists of 155 professors working at the department of Business \& Administration of this university college. In this sample, three types of professors can be distinguished: the full-time teachers, the full-time researchers, and the researcher-teachers. The fulltime teachers are the professors who only focus on teaching. The full-time researchers exclusively focus on doing research. The professors referred to as 'researcher-teacher' are the professors that do both teaching and research. Within the latter group, professors differ in the importance weight of each activity in their job description. In particular, there are some professors who combine a large teaching task with only a small research task. Other 'researcher-teacher'-professors are asked to attach more or less equal importance to both teaching and research. There are also professors with only a small teaching load and a substantial research task.

The fact that we only look at professors from the Faculty of Business \& Administration of the university college in our subsequent analysis, makes that the set of observations is rather homogeneous. This guarantees that the results of the performance evaluations will be less biased (for instance, by departmental characteristics, factors related to the educational program, etc.). The data were collected for the period 2006-2008 from three different sources: the questionnaire data administered by students to evaluate teaching effectiveness (i.e., SETs), departmental research evaluations, and administrative records.

The questionnaire data administered by students to evaluate teaching effectiveness are used to measure the professors' teaching performances. In particular, for each professor with teaching duties at the Faculty of Business \& Administration, an overall measure of teaching effectiveness (i.e., SETscore) is computed based on the evaluation questionnaires filled in (anonymously) by students attending the courses of the professor. The administration of the student questionnaires took place at the end of every semester in one of the last lecture sessions. The questionnaire to measure teaching effectiveness contains 16 statements, each of which measures a particular aspect of the professor's teaching performance. ${ }^{6}$ The composite SET-scores used in this study differ from traditional SETscores in that they account for the fact that some of the underlying teaching criteria are less important

\footnotetext{
${ }^{5}$ Typically, polytechnic universities in the UK and colleges in the US are comprehensive higher education institutions offering a broad range of (both professional and academic) education programs where courses also contain a research component.

${ }^{6}$ All items are measured on a five-point Likert scale that corresponds to a coding rule ranging from 1 (I completely disagree) to 5 (I completely agree).
} 
attributes of effective teaching than others. More precisely, contrary to traditional practice, SETscores are not calculated as arithmetic averages of the class average student item responses (which imply equal importance of all underlying teaching criteria). Instead, differential weights were assigned to the underlying teaching criteria according to their contribution to effective teaching as perceived by the two parties most involved in the teaching process (i.e., the students and the teachers). We refer to De Witte and Rogge (2011) and Rogge (2011), for a more detailed description of the questionnaire data and the differential weights used to construct the SET-scores.

The departmental research evaluations performed at the Faculty of Business \& Administration provide the measures for the research output of the professors with a research task. The Research Council of the faculty preferred to use a multi-criteria Research Evaluation Score (RES-score) which accounts for quality differences over research output criteria. More precisely, contrary to the typical, single-criterion measures of research performance often used in the academic literature and practice, the faculty Research Council decided (in dialogue with the researchers who are active at the faculty) to select nine different research output criteria to be considered in the research evaluations, each with a corresponding importance weight. Examples of research output criteria include publications in an international peer-reviewed journals, international books (based on own scientific work) as an author, finished research reports (externally funded by a commissioner), and research/discussion papers in the university's (but also other universities') discussion paper series. Both the selection of the research output criteria and their corresponding importance weights are made such as to reflect most faithfully the policy priorities of the faculty. For example, as publications in international peer-reviewed journals are considered as more essential for good research at the faculty, they are also more valued in the construction of the RES-score compared to, for instance, research/discussion papers. For a more detailed description of the composite, quality-adjusted RES-score, we refer to De Witte and Rogge (2010).

The official employee records contain information about each professor's teaching load and available time for doing research. The teaching load is proxied by the official percentage of time that a professor should invest in teaching. The available time for doing research is proxied by the official percentage of time that the professor is ought to spend at doing research. Both variables can be considered as inputs to the professor's production process. The higher the percentage allocated to a task, the more important is this task in the overall performance evaluation of the professor.

Regarding determination of the teaching and research tasks of the professors, it is important to point out that the faculty board and the research council of the department decided on the teaching and research time for the professors without considering the professors' past teaching and research performances in detail. As such, the time allocation can be considered as exogenous (and, thus, noncontrollable) to the professors. Professors who were already active in doing research in economics or management-related research areas received automatically 50\% research time. Junior professors received a $60 \%-40 \%$ division of research-teaching percentages. Professors who were already active in 
doing research but in other than economics-related research areas, were granted $20 \%$ research time. ${ }^{7}$ Next to the professors with both research and teaching interests, there are also professors that are fulltime teacher (i.e., no research time) or full-time researchers (i.e., no teaching duties). Here, full-time teachers are typically professors with a long track record at the institution and no interest in doing research, while full-time researchers are young academics with an exclusive focus on doing research (i.e., they are not responsible for providing lectures).

The official employee records also contain information about each professor's gender and age. In the literature, both these variables have been studied for their relation to the professor's teaching effectiveness and research productivity. ${ }^{8}$ As appears from Table 1, the results are inconclusive. With respect to the gender of the professor, for instance, some studies indicated that female professors do better than their male colleagues, while other studies showed that it is the other way around, with male professors outperforming their female colleagues. There are also studies that did not found any significant difference between males and females professors in terms of achieved teaching effectiveness and/or research productivity. A similar reasoning holds for the relationship between the background characteristic 'professor age' and teaching effectiveness and/or research productivity. Although we do not assume a direction on their influence on faculty productivity, the empirical application controls for this source of heterogeneity.

\section{$<$ Table 1 about here >}

Summary statistics on the two outputs of professor performance (i.e., SET- and RES-scores), the two inputs of the professor (i.e., teaching and research percentages), and the professor age and gender are presented in Table 1. Because we have full-time teaching and full-time research professors, the minimum- and maximum values for the teaching and research time percentages equal 0 and 1 . Correspondingly, the SET-scores (respectively RES-scores) equal 0 for the full-time researchers (respectively full-time teachers). Further, we find that the minimum-, first quartile-, and median value of the RES-scores equal 0 . This reveals the negatively skewed distribution of the research output among the professors. ${ }^{9}$ One also observes that $45 \%$ of the professors in the sample set are female and that the median age of the professors is 43 years.

\section{$<$ Table 2 about here >}

\footnotetext{
${ }^{7}$ Note that the percentages can be adjusted according to the total contract time. As an example, for a junior professor who is only working half-time at the department, instead of having research and teaching percentages of $60 \%$ and $40 \%$, percentages will be set equal to $30 \%$ and $20 \%$.

${ }^{8}$ It is important to note that this set of background variables is not exhaustive. The literature indicated also other background variables (i.e. research collaboration (e.g., Maske et al., 2003; and Ramos et al., 2007), family situation (e.g., children versus no children; see, for instance, Bellas \& Toutkoushian, 1999, and Hunter \& Leahey, 2010), etc.) that have the potential to influence the teaching and research performances of academics.

${ }^{9}$ This finding of heavily and negatively skewed distributions of research output among the professors should not be a surprise. Numerous studies reported similar findings at other institutions or in other fields of academic research (Ramsden, 1994; Daniel \& Fisch, 1990). In the literature, one also refers to this finding as Lotka's Law (after Lotka, 1926).
} 
To conclude this section, we visualize the SET- and RES-scores for the professors in Figure 2. In this figure, the full-time teachers and the full-time researchers are situated on respectively the horizontal axis (that is, with SET-score $>0$ and RES-score $=0$ ) and the vertical axis (that is, with SET-score $=0$ and RES-score $>0$ ). The professors with both teaching and research duties normally realize positive SET- and RES-scores and are thus situated in the quadrant (although, there are a few professors with both teaching and research duties that are situated on the horizontal axis as they did not realize any research output in the evaluation period). Note in Figure 2, four groups of professors. The first group consists of full-time researchers. Typically, these are young researchers in the early years of their academic career with rather low research outputs. The second group concerns full-time teachers and professors with both teaching and research duties that realize rather poor RES- and SET-scores. The third group consists of professors (both full-time teachers and professors with teaching and research duties) that realize high SET-scores but rather low RES-scores. The fourth group consists of academics with both teaching and research tasks that realize both high SET- and RES-scores.

$<$ Figure 2 about here >

\section{Estimating performance under scope economies}

To estimate the overall performance of professors under the presence of economies of scope between research and teaching, we start from the model of Cherchye et al. (2008), which is adapted to our specific setting. Specifically, as has been explained in previous section, our application considers two outputs: research output $y^{R}$ (i.e., research productivity as measured by the RES-score) and teaching output $y^{T}$ (i.e., overall teaching effectiveness as measured by the SET-score). Correspondingly, the application considers two inputs: research time input $x^{R}$ (i.e., research time percentage) and teaching time input $x^{T}$ (i.e., teaching time percentage). Research time and teaching time add up to total available time $x$ (i.e. $x=x^{R}+x^{T}$ ). At this point, it is worth stressing that, although we consider only two outputs and two inputs in our application, the methodology is effectively applicable to settings with multiple inputs and multiple outputs. ${ }^{10}$

\subsection{Performance measurement under scope economies}

Scope economies in teaching and research stem from externalities in production. In particular, research input $x^{R}$ benefits teaching effectiveness $y^{T}$ in addition to research productivity $y^{R}$. And, similarly, teaching input $x^{T}$ contributes to research productivity $y^{R}$ in addition to teaching

${ }^{10}$ In fact, Cherchye et al. (2008) originally considered a general setting with multiple inputs and multiple outputs. It can be verified that their general method boils down to the method described below for our specific setting. 
effectiveness $y^{T}$. This suggests the following production functions for research $\left(f^{R}\right)$ and teaching $\left(f^{T}\right)$ :

$$
y^{R}=f^{R} \quad x^{R}, x^{T} \quad \text { and } y^{T}=f^{T} \quad x^{R}, x^{T} \quad 1
$$

In words, the functions $f^{R}$ and $f^{T}$ give the maximum producible (research and teaching) output for any input $x^{R}, x^{T}$. Throughout, we will (only) assume that the functions $f^{R}$ and $f^{T}$ satisfy free disposability, i.e. more input never leads to less producible output. More formally, this means $x_{1}^{R}, x_{1}^{T} \geq x_{2}^{R}, x_{2}^{T}$ implies $f^{R} x_{1}^{R}, x_{1}^{T} \geq f^{R} x_{2}^{R}, x_{2}^{T}$ and $f^{T} x_{1}^{R}, x_{1}^{T} \geq f^{T} x_{2}^{R}, x_{2}^{T}$. No further assumption will be imposed on the production technology.

In our empirical analysis, we start from $K$ observed combinations of inputs and outputs (i.e., the $K$ professors in the sample set). For each observation $k(k=1, \ldots, K)$, the input and output is given as $x_{k}^{R}, x_{k}^{T}$ and $y_{k}^{R}, y_{k}^{T}$, respectively. Like before, total available time at observation $k$ is defined as $x_{k}=x_{k}^{R}+x_{k}^{T}$. We define the set of observations $S$ :

$$
S=\left\{k=1, \ldots, K \mid x_{k}^{R}, x_{k}^{T} \quad \text { is observed in combination with } y_{k}^{R}, y_{k}^{R}\right\}
$$

For production functions $f^{R}$ and $f^{T}$, we say an observation $k$ is efficient if it satisfies the following Pareto-Koopmans efficiency criterion:

$$
\begin{aligned}
& \text { for all } \mathrm{z}^{R}, z^{T} \quad \text { such that } \mathrm{z}^{R}+z^{T} \leq x_{k}: \\
& f^{R} z^{R}, z^{T}>\mathrm{y}_{k}^{R} \operatorname{implies} f^{T} z^{R}, z^{T}<\mathrm{y}_{k}^{T} .
\end{aligned}
$$

Stated differently, it is impossible to reallocate total time $x_{k}$ (obtaining $\mathrm{z}^{R}$ and $z^{T}$ ) to produce both more research output $\left(f^{R} z^{R}, z^{T} \geq \mathrm{y}_{k}^{R}\right)$ and more teaching output $\left(f^{T} z^{R}, z^{T} \geq \mathrm{y}_{k}^{T}\right)$, with at least one strict inequality. Clearly, Pareto-Koopmans efficiency is a natural criterion for evaluating teaching and research efficiency.

In practice, we do not observe the production functions $f^{R}$ and $f^{T}$, and thus we cannot directly check this efficiency criterion. Cherchye et al. (2008) developed a method that allows for checking whether there exists at least one specification of $f^{R}$ and $f^{T}$ (that satisfies the above free disposability assumption) such that observed behavior is effectively consistent with Pareto-Koopmans efficiency. The method is nonparametric in that it avoids specifying a (typically non-verifiable) functional/parametric form for the production functions $f^{R}$ and $f^{T}$. Following our above discussion, another attractive feature of the method is that it accounts for production externalities and 
thus for economies of scope in the production of research and teaching, because both functions $f^{R}$ and $f^{T}$ have the two inputs $x^{R}$ and $x^{T}$ as arguments.

Cherchye et al. (2008) define a necessary and sufficient condition for Pareto-Koopmans efficiency of a set of observations $S .{ }^{11}$ To formally state this condition, let us first define the 'output dominating reference set' $D^{k}$ for each observation $k$ :

$$
D^{k}=d^{R}, d^{T} \in S \times S \mid y_{d^{R}}^{R} \geq y_{k}^{R} \text { and } y_{d^{T}}^{T} \geq y_{k}^{T} \quad 4
$$

This set contains all combinations of observations $d^{R}, d^{T}$ such that $d^{R}$ dominating observation $k$ in terms of research output $\left(y_{d^{R}}^{R} \geq y_{k}^{R}\right)$ and $d^{T}$ dominating $k$ in terms of teaching output $\left(y_{d^{T}}^{T} \geq y_{k}^{T}\right)$. Obviously, we can have $d^{R}=d^{T}=d$ (i.e. the same observation $d$ dominates $k$ in both outputs).

Using $D^{k}$, the efficiency evaluation method solves the next linear programming model for each observation $k$ :

$$
\begin{array}{lc}
\theta_{k}=\max \theta & 5 \\
\text { s.t. } & \\
\theta x_{k} \leq x_{d^{R}}+x_{d^{T}} & \forall d^{R}, d^{T} \in D^{k}: d^{R} \neq d^{T} \\
\theta x_{k} \leq x_{d} & \forall d^{R}, d^{T} \in D^{k}: d^{R}=d^{T}=d \\
\theta \in \mathfrak{R} &
\end{array}
$$

The necessary and sufficient condition for Pareto-Koopmans efficiency of all observations in the set $S$ is that $\theta_{k}=1$ for all $k$. If $\theta_{k}<1$, we conclude that Pareto-Koopmans efficiency is rejected. Specifically, the value of $\theta_{k}$ gives the necessary input reduction (in casu time reduction) for observation $k$ to obtain consistency with the efficiency criterion. As such, $\theta_{k}$ provides a natural measure of efficiency for each individual observation $k$.

As a final note, the method described above bears interesting parallels to the so-called Data Envelopment (DEA) methodology. Specifically, the suggested efficiency evaluation model is formally similar to more standard DEA models. This will be a useful observation in view of our following discussion.

\footnotetext{
${ }^{11}$ Cherchye et al. (2008) only prove necessity of the condition. Cherchye et al. (2010) prove sufficiency for a formally similar model that applies to efficient consumer behavior. This sufficiency argument can be adapted to our production setting.
} 


\subsection{Conditional robust efficiency measurement}

Similar to the related DEA-model, the linear program model as in 5 suffers from two important limitations: its deterministic nature and the lacking correction for the impact of background characteristics (that is, characteristics non-controllable to the professor but that may nevertheless affect his/her opportunities to teach effectively and/or do good research).

The deterministic nature of the model has two drawbacks. Firstly, it does not allow us to define statistical properties of the overall performance scores of the professors $\theta_{k}$. For example, we cannot compute confidence intervals for these measures. Secondly, the deterministic nature of the model also makes that professors with outlying performance data or performance data affected by measurement error (if present in the sample set) can heavily influence the overall performance scores of all professors in the sample set. ${ }^{12}$ The second limitation of the linear program model, in that it does not account for the impact of background characteristics in the overall performance evaluations of professors, makes that obtained estimates of the overall performance scores may be considered as unfair. Particularly in situations where professor gender and/or age are significantly related to teaching effectiveness and/or research productivity, disfavoured professors may argue that a correction is warranted (given that both gender and age are two characteristics which are no doubt exogenous to the professor). ${ }^{13}$

To account for these issues, we adjust the above Model 5 by using the insights of Cazals et al. (2002), Daraio and Simar (2005, 2007a,b) and De Witte and Kortelainen (2009) for obtaining socalled 'robust order- $m$ ' (i.e., accounting for outlying observations) and 'conditional' (i.e., accounting for heterogeneity) performance measures. These insights were initially proposed in the setting of the DEA-models. However, given the formal similarity between the model of Cherchye et al. (2008) and traditional DEA-models, these insights are readily adapted to the current context. ${ }^{14}$

\footnotetext{
${ }^{12}$ While some may argue that outlying observations are highly interesting, and require additional research and inspection, we suggest mitigating their impact in performance evaluations. The reason is that the use of outlying performances as the sole benchmarks in the performance evaluations might be perceived by the professors as too ambitious, and that this perception might have an adverse effect on professor morale (demotivating instead of motivating professors to improve their performances).

${ }^{13}$ For instance, there are some studies (e.g., Centra \& Gaubatz, 2000; Basow, 2000; Wolfer \& Johnson, 2003) that found a student gender - teacher gender interaction in the evaluation of teaching effectiveness, with students ratings professors from the same gender slightly more favourably than professors from the opposite gender.

14 In what follows, we restrict ourselves to briefly sketching the basic idea of the robust and conditional measurement procedure. We refer to Cazals et al. (2002) and Daraio and Simar (2005, 2007a,b) and De Witte and Kortelainen (2009) for a more detailed explanation of the method; this also includes a discussion of attractive statistical properties (which carry over to our setting).
} 
In essence, the idea is to not consider the full set of observations for defining the overall performance score $\theta_{k}$. Instead, it is suggested to repeatedly consider subsamples of only $m$ observations for defining robust and conditional performance scores $\theta_{k}^{m}$. In particular, the performance measurement procedure as outlined in 5 is formulated in a Monte Carlo setting in which $B$ iterations $(b=1, \ldots, B)$ are performed (with $B$ a large number, in casu 500). Each of the iterations involves two steps. In a first step, $m$ observations are drawn (with replacement and with a probability depending on the value of the observation for the background variables on which the performance evaluation is being conditioned, see below) from the full set of observations. Correspondingly, this subsample of $m$ observations defines the set $D^{k, m} \subseteq D^{k}$ (with $\left|D^{k, m}\right|=m$ ) which is then used, in a second step, to compute the overall performance score $\theta_{k}^{b, m}$ by means of the linear programming problem in model 5 . For each professor $k$, the robust and conditional performance measure $\theta_{k}^{m}$ is computed as the average value of $\theta_{k}^{b, m}$ defined over the $B$ iterations.

The probability with which the observations can be drawn for selection in the subsample is dependent on the background characteristics (i.e., gender and age of the professor) on which the overall performance evaluation is being conditioned. In particular, the idea is to compare predominantly likes with likes. Formally, the probability for a professor to be considered in the subsample is being determined by a nonparametric kernel estimate around the background variables such that professors with similar values for the background characteristics have a larger probability of being selected in the subsamples. By doing so, we acknowledge that the background characteristics may productivity and teaching effectiveness.

In the empirical section below, we refer to 'robust' performance scores if model (5) is altered such that it accounts for outlying observations, while we refer to 'conditional' performance scores if model (5) additionally captures heterogeneity among observations.

\section{Results: estimating performance under scope economies in teaching and research}

As scope economies may be present in the teaching and research activities of some some professors, it is interesting to assess their overall performance under the assumption of scope economies and compare whether the evaluation outcomes differ substantially from the outcomes computed without making this assumption in the computations. Table 3 presents the results in which we both ignore scope economies and account for them in the performance evaluations.

$<$ Table 3 about here > 
First, we ignore the presence of scope economies. Technically, this corresponds to removing the first constraint of program (5) (i.e. $\left.\theta x_{k} \leq x_{d^{R}}+x_{d^{T}} \quad \forall d^{R}, d^{T} \in D^{k}: d^{R} \neq d^{T}\right){ }^{15}$ Clearly, because this obtains a linear programming model with one constraint less, the performance scores can only be equal or increase if we do not account for scope economies. The summary statistics of the evaluation outcomes are presented in the first and the second column of Table 3. The first column displays the evaluation outcomes as computed by the deterministic version of the Model 5 (i.e., without the robustification as presented in Section 4.2). The median professor can increase its performance by $6 \%$ (i.e., median value for $\theta_{k}=0.939$ ) if he/she would work as efficient as his/her best practice. The least performing professor can increase his/her performance score by $12 \%$.

As mentioned previously, this deterministic version of the model is non-robust in the sense that it does not correct for the possible presence of professors with performance data that is atypical and/or affected by measurement errors. As in academia outlying observations are likely since some professors publish significantly more or teach much better than other professors (or due to irregularities in the registration of the professor performances), some mitigation for the impact of outlying observations in the performance evaluation seems warranted. For instance, a detailed study of the teaching and research performances of the professors working at the Faculty of Business \& Administration, learned that there are some professors that realized very good teaching and/or researcher performances compared to the colleagues (e.g., recall the observation made earlier that the distribution of the research performances among the professors is heavily and negatively skewed). ${ }^{16}$

The summary statistics of the overall performance scores as computed by the robust version of the Model 5 (yet, without assuming scope economies) are presented in the second column of Table 3. The robust version accounts for a-typical observations. The results show that the potential efficiency increase for the median observation equals approximately $1 \%$ (i.e., the median $\theta_{k}^{m}=0.994$ ). After reducing the influence of outliers, the least performing professor could increase its performance by about $5 \%$.

At the Faculty of Business \& Administration of the university college at hand, as mentioned previously, some professors are allowed to only teaching while others are asked to do only research and other are required to combine both activities. As there is ambiguity on whether or not there are positive spillovers from research to teaching and vice-versa (and, thus, as positive spillovers may be present), we should account for the presence and absence in scope in the activities of professors. Indeed, professors do not voluntary chose to concentrate only on teaching or research, but are asked to do so by the faculty board. As it is not a voluntary decision and as, if positive spillovers would

\footnotetext{
${ }^{15}$ See Cherchye et al. (2008) for a detailed discussion. For ease of exposition we do not repeat the technical argument here.

16 Measurement errors might be present in the data as there are examples of professors whose registered teaching/research performances are probably not in correspondence with the actual teaching/research performance.
} 
actually hold, it would be more difficult for full-time teachers and full-time researchers to attain a similar performance score compared to the 'teacher-researcher' professors, the performance evaluation system should control for possible scope economies.

The results of the performance estimations under the assumption of scope economies are presented in column 3-5 of Table 3. The deterministic (non-robust) results reveal a median value for the inefficiency in the overall performance of the professors of $17 \%$ (i.e., $\theta_{k}=0.8310$ ). This is lower than the estimates ignoring scope. A nonparametric correlation between the traditional estimates (column 1) and the scope assumption estimates (column 3) indicates a significant positive correlation 0.81 (significant at $1 \%$-level). Note further that the minimum value of 0.7971 for $\theta_{k}^{m}$ is considerably lower than the one that is observed in the performance evaluations without accounting for scope economies.

Mitigating the influence of outlying and atypical observations slightly decreases the average estimated performance of academics. The median value for the robust inefficiency estimate increases to $4 \%$ (i.e., $\theta_{k}^{m}=0.9628$ ). In other words, in the presence of scope economies between teaching and research, the median academic can increase its teaching and research performance by $4 \%$ if he/she would work as efficient as the best practice. We observe a non-significant correlation between the robust estimations with and without the scope assumption. As the robust performance measure is estimated by resampling, this is not surprising.

In a final specification, we account both for scope economies and for the two aforementioned background characteristics which might influence the performance scores: professor gender and age. As can be seen from the fifth column in Table 3, this boosts the performance scores to a level where inefficiency vanishes (i.e., $\theta_{k}^{m}=0.9932$ ). In particular, once controlled for scope economies between teaching and research, for gender and age, the estimated overall performance scores indicate that the average academic can only increase its performance by $1 \%$. Surprisingly, the underlying data correlate significantly (at 1\%-level) with the deterministic estimates ignoring scope (nonparametric correlation of 0.33 ), the robust ignoring scope (correlation of 0.22 ) and the deterministic estimates accounting for scope (correlation of 0.46). In other words, it seems that the conditional estimates allowing for scope economies pull the efficiency estimations to a (in nominal terms) higher level.

\section{Conclusion}

The purpose of this paper was to develop an evaluation system that integrates both the teaching and research performances of professors, thereby accounting for the possible interrelationship (and, more in particular, the possible presence of scope economies) between both activities. We advocated the non-parametric model by Cherchye et al. (2008). This model draws on the popular Data Envelopment Analysis methodology (DEA). The key feature of this model is that it allows us to account for possible scope economies between evaluated activities in performance assessments. In the context of evaluating overall performances of university faculty, this means that we control for possible positive 
spillover effects between teaching and research activities. As the original Cherchye et al. (2008) model is deterministic it suffers from the drawback that estimated overall performance scores are sensitive to inconvenient influences (such as professors with atypical performances or measurement errors in the data) and uncorrected for the differences in background conditions (e.g., professor gender and age). To solve for both these limitations, the scope economies model that is used in this paper is further adjusted based on new insights of Cazals et al. (2002), Daraio and Simar (2005, 2007a, 2007b), and De Witte and Kortelainen (2009). The resulting model makes that estimations of the overall performance scores of professors are not only accounting for the possible presence of scope economies but are also robust to influences of outlying observations or differences in background characteristics. The estimation results reveal that overall the performance scores decrease if the efficiency model directly accounts for scope.

We see multiple avenues for follow-up research. One interesting theme for future research would be to examine more closely how the professors actually combine teaching and research duties. Only by observing on how the professors organize and fill in both activities can we obtain more information on whether or not positive spillover effects exist between teaching and research. In the words of Jenkins et al. (1998 p. 13): "How academics conceive teaching and research may be central to understanding the relationships and how they might be linked; but this research is at an early stage". Another avenue for further research is the study of the performances of professors working at other university departments (and, thus, with other teaching and research interests) or expanding our study with other background variables that may affect how professor succeed in combining both the teaching and research activities. 


\section{Literature}

Allen, M. (1996). Research productivity and positive teaching evaluations: Examining the relationship using meta-Analysis. Journal of the Association for Communication Administration 2: 77-96.

Baek, S.-G., \& Shin, H.-J. (2008). Multilevel analysis of the effects of student and course characteristics on satisfaction in undergraduate liberal arts courses. Asian Pacific Education Review 9(4): 475-486.

Barnett, R. (1992). Linking teaching and research: A critical inquiry. The Journal of Higher Education 63(3): 619-636.

Basow, S. A. (2000). Best and worst professors: Gender patterns in students' choices. Sex Roles: A Journal of Research 43(5/6): 407-417.

Becker, W.E., \& Kennedy, P.E. (2005). Does teaching enhance research in economics? The American Economic Review 95(2): 172-176.

Bellas, M.L., \& Toutkoushian, R.K. (1999). Faculty time allocations and research productivity: Gender, race and family effects. The Review of Higher Education 22: 367-390.

Bogetoft, P. (1996). DEA on relaxed convexity assumptions. Management Science 42: 457-465.

Braxton, J.M. (1996). Contrasting perspectives on the relationship between teaching and research. New Directions for Institutional research (Vol. 2). San Francisco: Jossey-Bass: 5-14.

Brew, A. (2001), The nature of research: inquiry in academic contexts, London: Routlegde/Falmer.

Cazals, C., Florens, J.P., and Simar, L. (2002). Nonparametric Frontier Estimation: A Robust Approach. Journal of Econometrics 106 (1): 1-25.

Centra, J.A. (1993). Reflective Faculty Evaluation: Enhancing Teaching and Determining Faculty Effectiveness. San Francisco: Jossey-Bass.

Centra, J.A., \& Gaubatz, N.B. (2000). Is there gender bias in student evaluations of teaching. Journal of Higher Education 71(1): 17-33.

Charnes, A. Cooper, W.W., \& Rhodes, E. (1978). Measuring the efficiency of decision making units. European Journal of Operational Research 2: 429-444.

Chen, Y., Gupta, A., \& Hoshower, L. (2006). Factors that motivate business faculty to conduct research: An expectancy theory analysis. Journal of Education for Business (March/April): 179-189.

Cherchye, L., De Rock, B., \& Vermeulen, F. (2008). Analyzing cost-efficient production behavior under economics of scope: A nonparametric methodology. Operations Research 56(1): 204221.

Cherchye, L., De Rock, B., \& Vermeulen, F. (2010). An Afriat theorem for the collective model of household consumption. Journal of Economic Theory 145(3): 1142-1163.

Cochran, H.H. Jr., Hodgin, G.L., \& Zietz, J. (2003). Student Evaluations of Teaching: Does Pedagogy Matter? Journal for Economic Educators 4(1): 6-18. 
Crawford, M., \& Macleod, M. (1990). Gender in the classroom: An assessment of the 'chilly climate' for women. Sex Roles 23: 101-122.

D’Appollonia, S., \& Abrami, P.C. (1997). Navigating student ratings of instruction. American Psychologist 52(11): 1198-1208.

Daniel, H.-D., \& Fisch, R. (1990). Research performance evaluation in the German university sector. Scientometrics 19(5-6): 349-361.

Daraio, C., \& Simar, L. (2005). Introducing Environmental Variables in Nonparametric Frontier Models: A Probabilistic Approach. Journal of Productivity Analysis 24 (1): 93-121.

Daraio, C., \& Simar, L. (2007a), Advanced robust and nonparametric methods in efficiency analysis: Methodology and applications. Series: Studies in Productivity and Efficiency. Springer.

Daraio, C., \& Simar, L. (2007b), "Conditional Nonparametric Frontier Models for Convex and Nonconvex Technologies: A Unifying Approach", Journal of Productivity Analysis, Vol. 28, pp. 13-32.

Davis, J.C., Huston, J.H., \& Patterson, D.M. (2001). The scholarly output of economists: A description of publishing patterns. Atlantic Economic Journal 29(3): 341-349.

De Witte, K., \& Kortelainen, M. (2009). Blaming the exogenous environment? Conditional efficiency estimation with continuous and discrete environmental variables. CES Discussion Paper Series DPS 08.33, MPRA Paper 14034.

De Witte, K., \& Rogge, N. (2010). To publish or not to publish? On the aggregation and drivers of research performance. Scientometrics 85(3): 657-680.

De Witte, K., \& Rogge, N. (2011). Accounting for exogenous influences in performance evaluations of teachers. Economics of Education Review 30 (4), 641-653.

Ellis, L., Burke, D.M., Lomire, P., \& McCormack, D.R. (2003). Student Grades and Average Ratings of Instructional Quality: The Need for Adjustment. The Journal of Educational Research 97(1): $35-40$.

Fabel, O. (2008). Research productivity in business economics: An investigation of Austrian, German and Swiss universities. German Economic Review 9(4): 506-531.

Fairweather, J.S. (1993). Faculty rewards reconsidered: the nature of tradeoffs. Change 25: 44-47.

Farrell, M.J. (1957). The measurement of productivity efficiency. Journal of the Royal Statistical Society, Series A CXX Part 3: 253-290.

Feldman, K. (1987). Research productivity and scholarly accomplishment of college teachers as related to their instructional effectiveness: A review and exploration. Research in Higher Education 26: 227-298.

Feldman, K. A. (1992). College students' views of male and female college teachers: Part 1 - evidence from the social laboratory and experiments. Research in Higher Education 3: 317-375.

Fox, M.F. (1992). Research, teaching, and publication productivity: Mutuality versus competition in academia. Sociology of Education 65(4): 293-305. 
Fox, M.F., \& Milbourne, R. (1999). What determines research output of academic economists? Economic Record 75: 256-267.

Friedrich, R., \& Michalak, S. (1983). Why doesn't research improve teaching? Some answers from a small liberal arts college. Journal of Higher Education 54: 145-163.

Gupta, B.M., Kumar, S., \& Aggarwal, B.S. (1999). A comparison of productivity of male and female scientists of CSIR. Scientometrics 45(2): 269-289.

Halsey, A.H. (1992). Decline of Donnish Dominion. Oxford, Clarendon Press.

Hattie, J., \& Marsh, H.W. (1996). The relationship between research and teaching: A meta-analysis. Review of Educational Research 66(4): 507-542.

Hattie, J., \& Marsh, H.W. (2004). One journey to unra vel the relationship between research and teaching. Research and Teaching: Closing the Divide? An International Colloquium. March 2004.

Hunter, L.A., \& Leahey, E. (2010). Parenting and research productivity: New evidence and methods. Social Studies of Science 40(3): 433-451.

Jenkins, A., Blackman, T., Lindsay, R., \& Paton-Saltzberg, R. (1998). Teaching and research: Student perspectives and policy implications. Studies in Higher Education 23: 127-141.

Kaschak, E. (1981). Another Look at Sex Bias in Students' Evaluations of Professors. Psychology of Women Quarterly 5: 767-772.

Koh, H.C., \& Tan, T.M. (1997). Empirical Investigation of the factors affecting SET results. International Journal of Educational Management 11(4): 170-178.

Krautmann, A.C., \& Sander, W. (1999). Grades and student evaluations of teachers. Economics of Education Review 18: 59-63.

Kremer, J. (1990). Construct validity of multiple measures in teaching, research, and service. Research in Higher Education 32: 351-361.

Lee, S., \& Bozeman, B. (2005). The impact of research collaboration on scientific productivity. Social Studies of Science 35(5): 673-702.

Liaw, S-H., \& Goh, K-L. (2003). Evidence and control of biases in student evaluations of teaching. The International Journal of Educational Management 17(1): 37-43.

Lindsay, R., Breen, R., \& Jenkins, A. (2002). Academic research and teaching quality: the views of undergraduate and postgraduate students. Studies in Higher Education 27(3): 309-327.

Lotka, A.J. (1926). The frequency distribution of scientific productivity. Journal of the Washington Academy of Sciences 16(12): 317-324.

Manakyan, H., \& Tanner, J.R. (1991). A survey of finance faculty on the relationship between research productivity and perceived teaching effectiveness. Journal of Financial Education 20: 27-39. 
Marsh, H.W., \& Hattie, J. (2002). The relation between research productivity and teaching effectiveness, complementary, antagonistic, or independent constructs. The Journal of Higher Education 73(5): 603-641.

Marsh, H.W. (2007). Students' evaluations of university teaching: dimensionality, reliability, validity, potential biases and usefulness. in R.P. Perry and J.C. Smart (Eds.). The Scholarship of Teaching and Learning in Higher Education: An Evidence-Based Perspective (pp. 319-383), Springer.

Maske, K.L., Durden, G.C., \& Gaynor, P. (2003). Determinants of scholarly productivity among male and female economists. Economic Inquiry 41: 555-564.

Massy, W. F., \& Wilger, A.K. (1995). Improving Productivity. Change: 10-20.

Massy, W. F., \& Zemsky, R. (1994). Faculty discretionary time. Journal of Higher Education 65(1): $1-22$.

McPherson, M.A. (2006). Determinants of How Students Evaluate Teachers. Journal of Economic Education 37: 3-20.

Neumann, R. (1992). Perception of the teaching-research nexus: A framework for analysis. Higher Education 23(2): 159-171.

Neumann, R. (1993). Academic work: Perceptions of senior academic administrators. Australian Educational Researcher 20: 33-47.

Neumann, R. (1996). Researching the teaching-research nexus: A critical review. Australian Journal of Education 40: 5-18.

Noser, T.C., Manakyan, H., \& Tanner, J.R. (1996). Research productivity and perceived teaching effectiveness: A survey of economics faculty. Research in Higher Education 37(3): 299-321.

Ramos, R., Royuela, V., \& Suriňach, J. (2007). An analysis of the determinants in Economics and Business publications by Spanish universities between 1994 and 2004. Scientometrics 71(1): 117-144.

Ramsden, P. (1994). Describing and explaining research productivity. Higher Education 28: 207-226.

Robertson, J., \& Bond, C.H. (2001). Experiences of the relation between teaching and research: What do academics value? Higher Education Research \& Development 20(1): 5-19.

Rogge, N. (2011). Granting teachers the 'benefit-of-the-doubt' in performance evaluations. International Journal of Educational Management forthcoming.

Rowland, S. (1996). Relationships between teaching and research. Teaching in Higher Education 1: $7-20$.

Rugarcia, A. (1991). The link between teaching and research: Myth or possibility? Engineering Education 81: 20-2.

Rushton, J.P., Murray, H.G., \& Paunonen, S.V. (1983). Personality, research creativity, and teaching effectiveness in university professors. Scientometrics 5: 93-116. 
Sax, L.J., Hagedorn, L.S., Arredondo, M., \& Dicrisi, F.A. (2002). Faculty Research Productivity: Exploring the role of gender and family-related factors. Research in Higher Education 43(4): 423-446.

Scott, P. (1991). Beyond the dual-support system: Scholarship, research and teaching in the context of academic autonomy. Studies in Higher Education 16: 5-13.

Seldin, P. (1985). Changing practices in faculty evaluation. Jossey-Bass. San Francisco.

Smeby, J. (1998). Knowledge production and knowledge transmission. The interaction between research and teaching at universities. Teaching in Higher Education 3: 5-20.

Tanner, J., Manakyan, H., \& Hotard, D. (1992). Management faculty research productivity and perceived teaching effectiveness. Journal of Education for Business 67(5): 261-265.

Trice, A.J. (1992). The tensions between teaching and scholarship. Chronicle of Higher Education. p. B4.

Vidal, J., \& Quintanilla, M.A. (2000). The teaching and research relationship within an institutional evaluation. Higher Education 40(2): 217-229.

Westergard, J. (1991). Scholarship, research and teaching: A view from the social sciences. Studies in Higher Education 16: 23-28.

Wolfer, T.A., \& Johnson, M.M. (2003). Re-evaluating student evaluation of teaching: The teaching evaluation form. Journal of Social Work Education 39(1): 111-121.

Zaman, M. Q. (2004). Review of academic evidence on the relationship between teaching and research in higher education. Research Report No. 506. Department of Education and Skills. London. 
Table 1: The relationship between professor gender/age and teaching effectiveness/research productivity

\begin{tabular}{|c|c|c|}
\hline & Teaching effectiveness (SET-scores) & Research productivity (RES-scores) \\
\hline \multirow{5}{*}{ Professor age } & Positive correlation: & Positive correlation: \\
\hline & McPherson (2006), d'Apollonia \& Abrami (1997) & l \\
\hline & Negative correlation: & Negative correlation: \\
\hline & Baek \& Smith (2008), Cochran et al. (2003) & Sax et al. (2002), Fabel (2008 \\
\hline & $\begin{array}{l}\text { Insignificant correlation: } \\
\text { Ellis et al. (2003), Liaw \& Goh (2003), Koh \& Tan } \\
\text { (1999) }\end{array}$ & $\begin{array}{l}\text { Insignificant correlation: } \\
\text { Ramsden (1994), Gupta et al. (1999) }\end{array}$ \\
\hline \multirow{8}{*}{ Professor gender } & Higher SETs for females: & Higher RES-scores for females: \\
\hline & Crawford \& MacLeod (1990), Kaschak (1981) & l \\
\hline & Higher SETs for males: & Higher SETs for males: \\
\hline & Feldman (1992) & Ramsden (1994), Sax et al. (2002), Maske et al. \\
\hline & Insignificant correlation: & $(2003)$ \\
\hline & $\begin{array}{l}\text { Krautmann \& Sander (1999), Ellis et al. (2003), } \\
\text { Liaw \& Goh (2003) }\end{array}$ & \multirow{3}{*}{$\begin{array}{l}\text { Insignificant correlation: } \\
\text { Chen et al. (2006), Lee \& Bozeman (2005), Davis } \\
\text { et al. (2001) }\end{array}$} \\
\hline & Gender interaction: & \\
\hline & $\begin{array}{l}\text { Centra \& Gaubatz (2000); Basow (2000); } \\
\text { Wolfer \& Johnson (2003) }\end{array}$ & \\
\hline
\end{tabular}


Table 2: Descriptive statistics

\begin{tabular}{|c|c|c|c|c|}
\hline & \multicolumn{2}{|c|}{ Inputs (exogenous to the professor) } & \multicolumn{2}{|c|}{ Outputs } \\
\hline & Teaching time $(\%)$ & Research time (\%) & Teaching (SET-) score & Research (RES-) score \\
\hline Minimum & $0.00 \%$ & $0.00 \%$ & 0.00 & 0.00 \\
\hline First quartile & $64.48 \%$ & $0.00 \%$ & 2.99 & 0.00 \\
\hline Median & $100.00 \%$ & $0.00 \%$ & 3.51 & 0.00 \\
\hline Third quartile & $100.00 \%$ & $25.00 \%$ & 3.91 & 6.00 \\
\hline Maximum & $100.00 \%$ & $100.00 \%$ & 4.76 & 418.00 \\
\hline Stdev. & $30.36 \%$ & $28.68 \%$ & 1.13 & 61.65 \\
\hline Number of obs. & 155 & 155 & 155 & 155 \\
\hline
\end{tabular}


Table 3: Summary statistics of results

\begin{tabular}{lcc|ccc}
\hline \hline & \multicolumn{2}{c|}{ Ignoring scope } & \multicolumn{3}{c}{ Accounting for scope } \\
& Deterministic & Robust & Deterministic & Robust & Conditional robust \\
\hline Minimum & 0.8850 & 0.9517 & 0.7971 & 0.8614 & 0.9391 \\
First quartile & 0.9149 & 0.9867 & 0.8310 & 0.9505 & 0.9797 \\
Median & 0.9390 & 0.9942 & 0.8310 & 0.9628 & 0.9932 \\
Third quartile & 1.0000 & 1.0000 & 0.9382 & 0.9717 & 1.0000 \\
Maximum & 1.0000 & 1,0549 & 1.0000 & 1.0932 & 1.0560 \\
\hline \hline
\end{tabular}


Figure 1: Robust overall performance scores (accounting for scope)

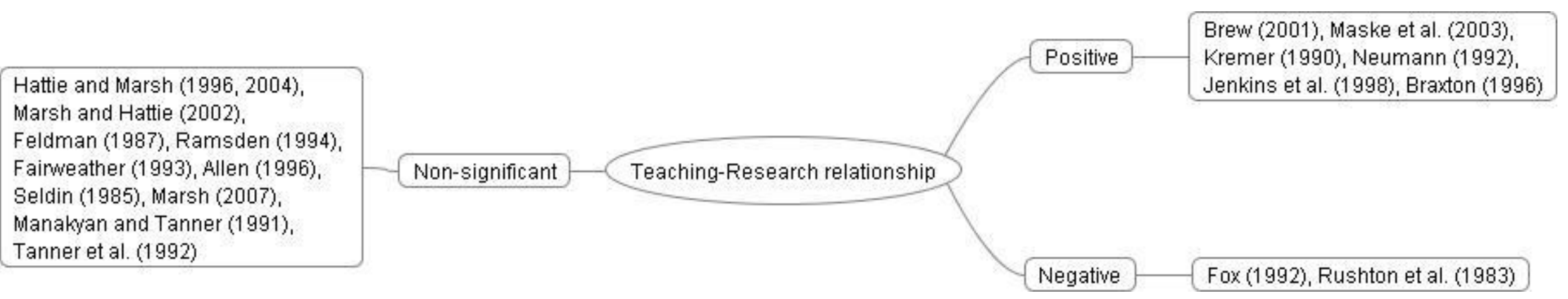


Figure 2: Robust overall performance scores (accounting for scope)

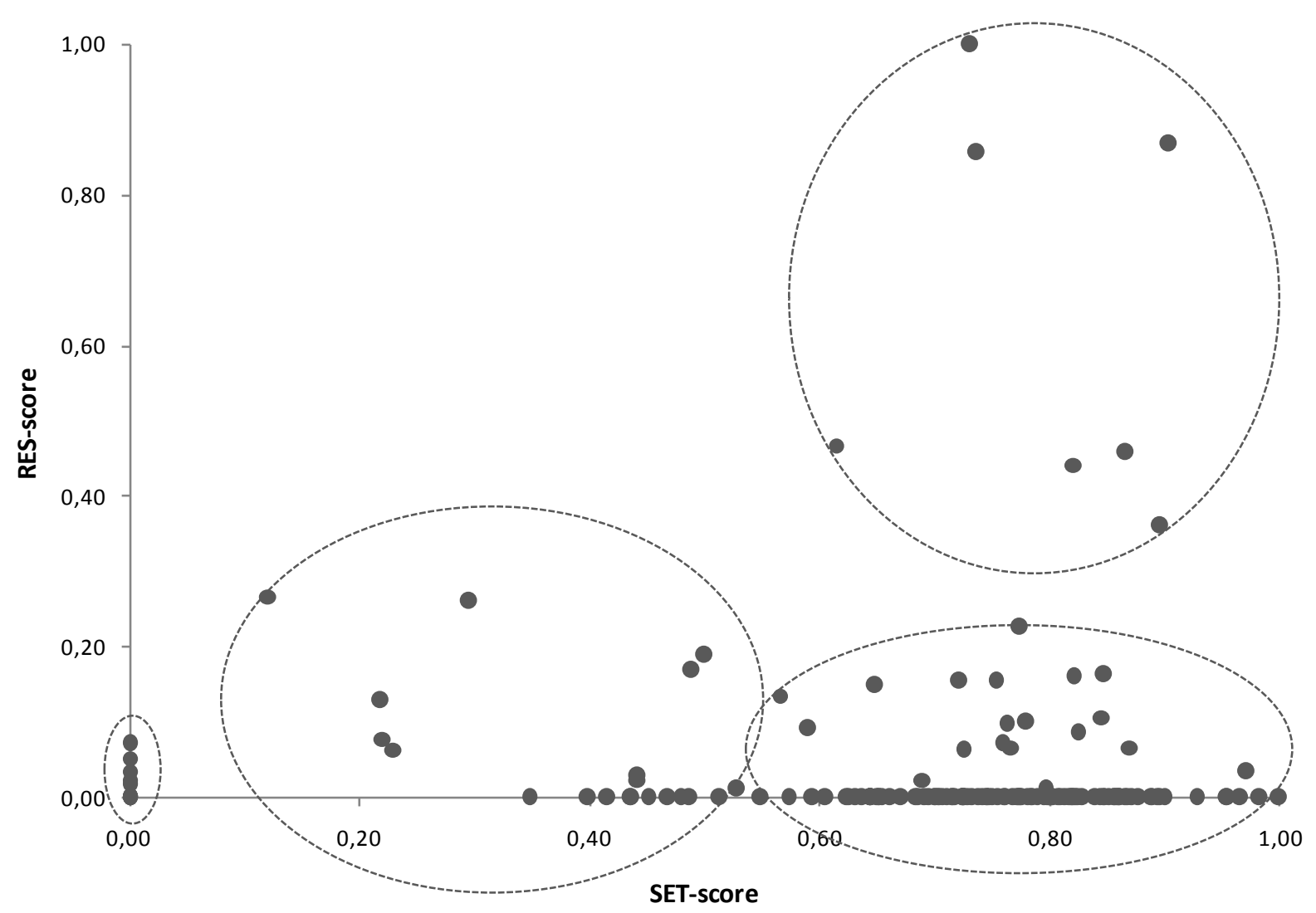

